\title{
SUPPORTING EMOTION SOCIALIZATION SKILLS OF PRESCHOOL TEACHER CANDIDATES
}

\author{
Aysel Esen Coban, Ayca Ulker Erdem, \& Tulay Ilhan Iyi \\ Department or Early Childhood Education, Hacettepe University, Turkey
}

\begin{abstract}
This research aims to investigate early childhood teacher candidates' emotion socialization skills and to provide support to improve those skills. As related to the basic purpose of the study, qualitative research method was used for sample selection, data collection and data analysis process. Participants were 22 early childhood teacher candidates. A semi structured interview, a focus group interview and reflective journals were used for data gathering. Data was analyzed by using content analysis. Findings showed that training support was effective for improving their emotion socialization skills. While teacher candidates' socialization practices of positive emotions enriched, they claimed to use more supportive socialization practices of negative emotions after the training. This study is believed to have direct impacts on preservice and in-service training plans and indirect effects on early support for children's emotional development.
\end{abstract}

Keywords: Emotion socialization, preschool teaching, teacher candidates, teacher training.

\section{Introduction}

Children express their positive and negative feelings in a variety of ways in their daily lives and receive reactions from their immediate surroundings to these feelings. This process, which is called emotion socialization, refers to parents' teaching about emotions by responding to children's emotions (Eisenberg, Cumberland \& Spinrad, 1998) and the way that the parents express their feelings and become a model for children (Morris, Silk, Steinberg, Myers \& Robinson, 2007). In this period, guiding the positive and negative emotional experiences of the child and giving supportive reactions to their feelings will positively affect the emotional and social development of the child. Studies conducted with parents show that positive and rewarding responses of parents to their children's feelings increased their positive social behaviors (Denham \& Kochanoff, 2002) while the children of mothers who did not accept the feelings of their children and ignored their emotions were less able to regulate their emotions and accordingly they showed more aggressive behavior (Ramsden ve Hubbard, 2002).

While this process is limited by the parents in early years, by the start of the preschool period, peers and teachers are included in the emotional interactions of the child. Therefore, teachers are also considered as important emotion socialization agents for children. Although there are many studies on the parents' emotion socialization strategies, little work has been found with preschool teachers who have an important role on the development of children in early ages. Researchers propose that preschool teachers have a great deal of emotion socialization opportunities for children during daily interactions (Denham, Bassett, \& Zinsser, 2012) and highlighted that they assume to provide an emotion-focused care (Ahn, 2005; Ahn \& Stifter, 2006; Hyson, 2002). However, although the importance of teacher-child interaction in terms of learning environments has been revealed; teacher training programs have limited content (such as Incredible Years, PATHS, I Can Problem Solve) on promoting emotional development of children through interactions.

Similarly, early childhood teacher candidates' emotion socialization practices were less focused which is a significant gap in the national and international literature. In this regard, it is thought that developing training programs to increase teacher candidates' awareness towards emotion socialization and to enable them to gain appropriate emotion socialization skills will contribute to the field. Considering that teachers' emotion socialization practices are important models for children's emotional experiences it is important to draw attention to these skills at the stage of gaining their professional identity and recommended to gain awareness and skills through practical courses. On this basis literature offers certain methods such as reflective supervision (Emde, 2009), mindfulness, emotional intelligent training, stress reduction and teaching new skills (Jennings \& Greenberg, 2009). Within this context, this study firstly aimed to investigate teacher candidates' emotion socialization strategies and to provide support for improving their emotion socialization skills with a 10-session training which is based on the techniques defined in the literature. 


\section{Method}

As related to the basic purpose of the study, qualitative research method was used for sample selection, data collection and data analysis process in this study. A case study approach was conducted to deeply examine participants' emotion socialization practices and the effectiveness of the proposed support. Creswell (2007) states that case study is an approach in which the researcher examines one or more cases in depth, over a limited time, using multiple data collection tools and defines themes related to the cases.

\subsection{Procedure}

The research process for this study began with the sample selection. As a part of a larger research study which aims to develop social emotional learning/ teaching practices of early childhood teacher candidates, an interaction group was announced and a purposeful sample was identified. The sample for this study comprised 22 early childhood teacher candidates studying at a government based university in Ankara, Turkey. They were all studying preschool teaching at different class levels in spring term of 2018.

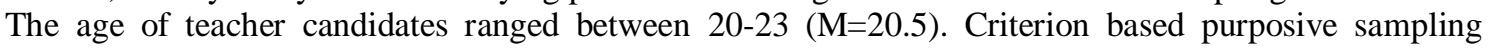
technique was used to select the participants. Depending on the aim of the study, all participants were considered to have an ongoing teaching experience at a public kindergarten with 3-6 year old children. Oral consents and the informed assents of all participants were obtained. Additionally, a group protocol was signed in order to protect participant rights in the group process with an emphasis on confidentiality. Then semi-structured interview forms were presented to the participants to assess their baseline emotion socialization skills and practices. The form compiled open ended questions in order to gain information about teacher candidates' emotion socialization skills. The type of questions asked to participants during the research were, but not limited, as follows: (1) children's challenging emotions faced in their practices, (2) their own responses to children's negative emotions, (3) their own responses to children's positive emotions. The aim of the initial interviews was to define participants' current emotion socialization levels.

As a next step, participants attended to a 10-session training which was formed and piloted prior to the current research. The first author directed the group with two co-authors as co-facilitators. This training included activities to teach new skills for responding children's emotions through psychoeducation and experiential techniques such as play, drama and art. This training was considered to improve professional development and socio-emotional learning/teaching practices. Sessions covered certain themes which are important for gaining supportive emotion socialization skills. The content of the first five sessions is as follows respectively; an intro session with an emphasis on the participants' desire to be an early childhood teacher; a psychoeducation session about negative emotions and theoretical base of emotion socialization, a creative drama session about the basic emotion socialization strategies and an experiential session about individual emotional awareness. Fifth and sixth sessions covered some exercises for highlighting the importance of meta-emotion philosophy and sampling how to develop empathy. After that, sessions continued with a reflective supervision session in which participants brought their own examples from the field practice; an emotion coaching approach to anger and anxiety; a prompter game to make participants notice different emotional experiences with lower and higher intensity and finally a focus group session to explore participants' metacognitions about their emotion socialization skills. This was an evaluation session and after group interactions were completed semi structured interviews were implemented as posttests to investigate the change in participants' emotion socialization levels. Additionally, participants were asked about their observations, experiences and practices on emotion socialization throughout individual reflective journals during the research process.

\subsection{Data analysis}

The findings of this study were derived from interviews and reflective journals to ensure the triangulation. Content analysis was used for analyzing the interview data. Participants' reflections in reflective journals were used as supportive evidence to show the change in their emotion socialization skills and representative quotations from the interview and reflections are presented in the findings.

Data analysis process involved the researchers working on the themes and the data constantly until an inclusive set of major themes are established (Creswell, 2007). The fundamental process in content analysis was to bring together similar data in the context of certain themes and categories to interpret them in a way that the reader can understand (Yıldırım \& Şimşek, 2011). In the second stage; reduced data was used and it was tried to reveal patterns between the data. In this regard the whole interview data was read by two researchers and analyzed under the codes and the themes generated from the theoretical background of socializing positive and negative emotions and previous research (Ahn \& Stifter, 2006; Kılıç, 2015). In order to ensure the reliability an independent researcher was asked to analyze $15 \%$ of data. Reliability was measured by the technique suggested by Miles and Huberman (1994) as .92 which is an agreeable level for social research. 


\section{Findings}

According to the information obtained from the interview, it is seen that the most compelling emotion experienced by teacher candidates is anger $(f=11)$, which is followed by sadness $(f=6)$, curiosity $(f=2)$ and anxiety $(f=1)$. The themes and codes related to the emotion socialization reactions adopted by the teacher candidates towards those challenging emotions and also children's positive emotions before the training support are presented in Table 1.

Table 1. Themes and codes about emotion socialization skills of participants before the training.

\begin{tabular}{|c|c|c|c|}
\hline & Pre-test & & \\
\hline Theme & Sub-theme & Code & Frequency \\
\hline \multirow{2}{*}{$\begin{array}{l}\text { Socializing } \\
\text { positive } \\
\text { emotions }\end{array}$} & Sharing & $\begin{array}{l}\text { - sharing emotion } \\
\text { - asking for sharing the emotion with friends }\end{array}$ & 18 \\
\hline & Emotion focused response & $\begin{array}{l}\text { - find out the reason of the emotion } \\
\text { - talking about the emotion }\end{array}$ & 9 \\
\hline \multirow[t]{5}{*}{$\begin{array}{l}\text { Socializing } \\
\text { negative } \\
\text { emotions }\end{array}$} & Solution focused response & $\begin{array}{l}\text { - trying to solve the problem } \\
\text { - look for a solution } \\
\text { - solving problem for the child }\end{array}$ & 8 \\
\hline & Distraction & $\begin{array}{l}\text { - eliminating the reason } \\
\text { - focusing on the solution by ignoring emotion }\end{array}$ & 6 \\
\hline & Minimizing & $\begin{array}{l}\text { - using behavior change techniques } \\
\text { - find out the reason of the emotion and make } \\
\text { suggestions } \\
\text { - using I language } \\
\text { - encouraging children to show empathy to peers }\end{array}$ & 4 \\
\hline & Emotion focused response & $\begin{array}{l}\text { - appreciating the emotion } \\
\text { - giving opportunity to talk about emotion } \\
\text { - expressing the emotion its normal } \\
\text { - showing empathy } \\
\text { - considering the emotion }\end{array}$ & 4 \\
\hline & Physical affection and comfor & - comforting, calming down, physical contact & 2 \\
\hline
\end{tabular}

Table 1 shows that sharing and emotion focused response was used for the socialization of positive emotions before the training. However, prior to the support, teacher candidates' strategies for socializing negative emotions were mainly solution focused response, distraction and minimizing. Positive emotion socialization responses such as emotion focused response and physical affection and comfort were less used. The participants' own statements about these responses are as follows:

"If there is a negative external factor, I try to eliminate it. If the problem is not related to the environment, I find the problem and apply behavior management methods."(TC2, interview) interview)

"I try to solve, eliminate or differentiate the event that causes children to feel that way." (TC5,

"I noticed a few mistakes I made during my practice, I was very uncomfortable. I realized that I didn't give the children any opportunity, and I showed them directly the solution." (TC3, reflective journal).

When Table 1 and 2 are assessed together, it is observed that the training was effective for improving teacher candidates' emotion socialization skills. Table 2 shows that strategies adopted by teacher candidates towards positive emotions was enriched after the support. On the other hand, it is seen that the quality of the reactions they adopt in socializing negative emotions has changed. Teacher candidates interiorize more supportive emotion socialization strategies such as physical affection and comfort, helping to regulate negative emotion, problem focused response, emotion focused response, labeling, positive interaction and modeling after the training. Sample quotations showing these changes are as follows:

"[Previously] I was more focused on problem solving. After having knowledge about socialization of emotion (...) I started to give place to what I learned in my practice. I guided children by using the emotion coaching method. (TC1: reflective journal)"

"During my practice, I applied the steps of labeling the emotion, defining the situation, asking questions that would lead to a solution, and becoming a model. Realizing that the child is getting calm and these steps work has shown that I must continue to follow these steps in all my teaching experiences. " (TC2, reflective journal)

"I was getting into a lather when the kids got angry before. I could not reach them. I learned what to say to the child when I recognized the concept of emotion socialization (...) when the child feels sorry, 
instead of understanding his sorrow, giving a reward to him and passing it off, causes the child not to define his sense." (TC17, reflective jorunal)

"I was repeating a very frequent mistake and trying to make children forget their negative feelings and distract them. I was exaggerating their positive feelings; much more enthusiastic way I was transferring them. Now, I tell children that the emotions they experience are actually very natural and give them time to feel that emotion." (TC20, reflective journal)

Table 2. Themes and codes about emotion socialization skills of participants after the training.

\begin{tabular}{|c|c|c|c|}
\hline \multicolumn{4}{|c|}{ Post-test } \\
\hline Theme & Sub-theme & Code & Frequency \\
\hline \multirow[t]{2}{*}{$\begin{array}{l}\text { Socializing } \\
\text { positive } \\
\text { emotions }\end{array}$} & Sharing & $\begin{array}{l}\text { - sharing the emotion } \\
\text { - asking for sharing the emotion with friends } \\
\text { - projecting the emotion but not magnifying }\end{array}$ & 22 \\
\hline & Emotion focused response & $\begin{array}{l}\text { - find out the reason of the emotion } \\
\text { - considering the emotion } \\
\text { - appreciating the emotion } \\
\text { - talking about the emotion } \\
\text { - projecting the emotion physically } \\
\text { - asking for accompanying emotions } \\
\text { - enabling the child to understand the emotion } \\
\text { - permitting the child to express emotion }\end{array}$ & 13 \\
\hline \multirow[t]{8}{*}{$\begin{array}{l}\text { Socializing } \\
\text { negative } \\
\text { emotions }\end{array}$} & $\begin{array}{l}\text { Physical affection and } \\
\text { comfort }\end{array}$ & $\begin{array}{l}\text { - giving time to calm down } \\
\text { - comforting, calming down, physical contact } \\
\text { - giving trust }\end{array}$ & 14 \\
\hline & $\begin{array}{l}\text { Helping to regulate } \\
\text { negative emotion }\end{array}$ & $\begin{array}{l}\text { - finding the solution together } \\
\text { - permitting the child to experience the emotion } \\
\text { - searching for a solution } \\
\text { - enabling child to cope with the emotion } \\
\text { - expressing the emotion its normal } \\
\text { - enabling the child to understand the emotion }\end{array}$ & 12 \\
\hline & Problem focused response & $\begin{array}{l}\text { - observing } \\
\text { - finding out reason of the emotion } \\
\text { - finding out the problem } \\
\text { - asking questions }\end{array}$ & 9 \\
\hline & $\begin{array}{l}\text { Showing empathy to } \\
\text { negative emotion }\end{array}$ & $\begin{array}{l}\text { - appreciating the emotion } \\
\text { - projecting the emotion } \\
\text { - showing empathy }\end{array}$ & 5 \\
\hline & Emotion focused response & $\begin{array}{l}\text {-talking about emotion (physical projections, } \\
\text { accompanying other emotions) } \\
\text {-considering the emotion, appreciating the emotion }\end{array}$ & 4 \\
\hline & Labeling & $\begin{array}{l}\text { - asking to label the emotion } \\
\text { - naming the emotion }\end{array}$ & 2 \\
\hline & Positive interaction & - positive communication & 2 \\
\hline & Modeling & $\begin{array}{l}\text { - modelling } \\
\text { - guiding }\end{array}$ & 2 \\
\hline
\end{tabular}

\section{Discussion}

The aim of this study was to investigate and support emotion socialization strategies of early childhood teacher candidates. The findings showed that their response repertoires were enriched. Moreover, teacher candidates were found to interiorize more supportive socialization strategies such as physical affection and comfort, emotion focused response, labeling, helping to regulate negative emotion, problem focused response, positive interaction, modelling and showing empathy to negative emotions. At the same time, the teacher candidates stated that they felt more competent in coping with children's negative emotions and started to use these supporting strategies in their teaching practices. As a result of the relational culture structure of Turkey, different from the Western literature, pre-service teachers seemed to socialize positive emotions through suggesting to share with others and making conscious efforts in order to maintain children's positive mood. In addition to this, prior to the training, teacher candidates reported that they often focused on the event which elicit negative emotion and used solution focused response so that they could eliminate the cause of the negative emotion. Solution focused response is different from the non-supportive emotion socialization responses defined in the literature and this could be explained by the didactic and behavior-focused early childhood learning environment which is commonly observed in 
Turkey. This approach, which is used as a way of preventing misbehaviors in learning environments, provides an idea that teacher candidates focus on behavior by ignoring emotion. However, it is known that children express and control their feelings much easier when teachers comfort their negative emotions (Gottman, Katz \& Hooven, 1997). According to Furman (1995) children might not know emotion words and might not be able to verbally express their feelings. Therefore, teachers' definitions and labels of their emotions is highly important in terms of children's recognition of their own emotions. At this point, the current study's findings revealed that after the support, teacher candidates adopted problem-focused responses and helping to regulate negative emotion strategies rather than searching for solutions to help children coping with their emotions. Similarly, in Ahn's study (2005) it was concluded that when teachers help children for coping with their emotions and offer concrete suggestions, their pro-social development has improved. Considering the fact that the teacher candidates use non-supportive emotion socialization strategies before the training such as distraction and minimizing, training provided in this research was found to be effective in supporting teacher candidates' emotion socialization skills. Teachers play a very important role in terms of creating an environment that supports children's emotion regulation skills and ability to respond appropriately to the feelings of others (Hyson, 1994). Consistently, the current study showed that the support provided to the teacher candidates has increased their use of positive emotion socialization strategies. Thus, it is thought that this training will enable teacher candidates to create an environment that supports children's emotion regulation skills. With all these contributions, this study is believed to have direct impacts on pre-service and in-service trainings and indirect effects on early support for children's emotional development.

\section{References}

Ahn, H. J. (2005). Child care teachers' strategies in children's socialization of emotion. Early Childhood Development and Care, 175(1), 49-61.

Ahn, H. J. \& Stifter, C. (2006). Child care teachers' response to children's emotional expression. Early Education and Development, 17(2), 253-270.

Creswell, J. W. (2007). Qualitative inquiry and research design: Choosing among five approaches (2nd ed.). Thousand Oaks, CA, US: Sage Publications, Inc.

Denham, S. A., Bassett, H. H., \& Zinsser, K. (2012). Early childhood teachers as socializers of young children's emotional competence. Early Childhood Education Journal, 40(3), 137-143.

Denham, S.A. \& Kochanoff, A.T. (2002). Parental contributions to preschoolers' understanding of emotion. Marriage \& Family Review, 34(3-4), 311-343. doi: 10.1300/J002v34n03_06

Eisenberg, N., Cumberland, A., Spinrad, T.L. (1998). Parental socialization of emotion. Psychological Inquiry, 9(4), 241-273.

Emde, R. N. (2009). Facilitating reflective supervision in an early child development center. Infant Mental Health Journal, 30(6), 664-672.

Furman, R. A. (1995). Helping children cope with stress and deal with feelings. Young Children, 50(2), 33-41.

Gottman, J.M., Katz, L.F. \& Hooven, C. (1997). Meta-emotion: How families communicate emotionally. Mahwah, NJ: Lawrence Erlbaum Associates.

Hastings, P.D. \& De, I. (2008). Parasympathetic regulation and parental socialization of emotion: Bio-psychosocial processes of adjustment in preschoolers. Social Development, 17 (2). 211-237.

Hyson, M. C. (1994). The emotional development of young children: Building an emotion-centered curriculum. New York: Teachers College.

Hyson, M. (2002). Emotional development and school readiness. Professional Development, 57(6),76-78.

Jennings, P.A. \& Greenberg, M.T. (2009). The prosocial classroom: Teacher social and emotional competence in relation to student and classroom outcomes. Review of Educational Research, 79(1), 491-525.

Kilıç, Ş. (2015). Preschool teachers' emotional socialization responses to 4-6 year old Turkish preschoolers' emotional expressions. EJRE, 3(1). 53-63.

Miles, M, B., \& Huberman, A. M. (1994). Qualitative data analysis: An expanded sourcebook. (2nd ed). Thousand Oaks, CA: Sage

Morris, A. S., Silk, J. S., Myers, S.S., Steinberg, L.\& Robinson, L. R. (2007). Role of family context in the development of emotion regulation. Social Development, 16(2), 361-388. doi:10.1111/j.14679507.2007.00389.x

Ramsden, S. R. \& Hubbard, J.A. (2002). Family expressiveness and parental emotional coaching: their role in children's emotion regulation and aggression. Journal of Abnormal Child Psychology, 30(6), 657-667.

Yıldırım, A., \& Şimşek, H. (2011). Qualitative research methods in Social Sciences (8th. ed). Ankara: Seçkin Publishing. 